Narrative in Culture 



\section{Narrative in Culture}

Edited by

Astrid Erll and Roy Sommer

\section{DE GRUYTER}


ISBN 978-3-11-064611-5

e-ISBN (PDF) 978-3-11-065437-0

e-ISBN (EPUB) 978-3-11-065230-7

\section{Library of Congress Cataloging-in-Publication Data}

A CIP catalog record for this book has been applied for at the Library of Congress.

\section{Bibliographic information published by the Deutsche Nationalbibliothek}

The Deutsche Nationalbibliothek lists this publication in the Deutsche Nationalbibliografie; detailed bibliographic data are available on the Internet at http://dnb.dnb.de.

(C) 2019 Walter de Gruyter GmbH, Berlin/Boston

Typesetting: Integra Software Services Pvt. Ltd.

Printing and binding: CPI books $\mathrm{GmbH}$, Leck

Cover image: XXXX

www.degruyter.com 


\section{Contents}

Astrid Erll and Roy Sommer

A Tale of Two Concepts: Ansgar Nünning at Sixty - 1

Michael Basseler

Stories of Dangerous Life in the Post-Trauma Age: Toward a Cultural Narratology of Resilience - 15

Sibylle Baumbach

Mind the Narratives: Towards a Cultural Narratology of Attention - 37

Marion Gymnich

The End of the World (as We Know It)? - Cultural Ways of Worldmaking in Contemporary Post-Apocalyptic Narratives - 57

Jan Rupp

Plumbing Distant Spatiotemporal Scales: Towards an Econarratology of Planetary Memory in Narratives of the Global South -75

Birgit Neumann

Narrative Forms in the Age of the Anthropocene: Negotiating HumanNonhuman Relations in Global South Novels - 91

Sandra Heinen

Fact, Fiction, and Everything in-between: Strategies of Reader Activation in Postcolonial Graphic Narratives — 109

Carola Surkamp

'It's Not Our Opinion, It's the Opinion of Our roles' - Fremdverstehen

Revisited or: Where Foreign Language Education and Narratology Can Meet - 129

Hanne Birk

Narrative and Visual Resources of Culture in Contemporary Indigenous Children's Books from Australia — 149 
VI - Contents

Stella Butter

Troubling Justice: Narratives of Revenge - 165

Guido Isekenmeier

Erin Burnett in Mali: Bardic Television and the Genealogy of Cultural Narratology -185

Dorothee Birke

New Media Narratives: Olivia Sudjic's Sympathy and Identity in the Digital Age — 199

Bruno Zerweck

The 'Death' of the Unreliable Narrator: Toward a Functional History of Narrative Unreliability -215

Astrid Erll

Odyssean Travels: The Migration of Narrative Form (Homer - Lamb Joyce) 241

Janine Hauthal

A European Storyteller? Collective Narration in John Berger's Into Their Labours 269

Roy Sommer

Brexit as Cultural Performance: Towards a Narratology of Social Drama 293

Contributors -321 


\title{
Mind the Narratives: Towards a Cultural Narratology of Attention
}

\begin{abstract}
Taking its cue from current discourses on anxieties of (in)attention, and from the connections between attention, culture, and narrative, this essay introduces the conceptual and methodological framework for a cultural narratology of attention. As I argue, selective attention is not only a biological necessity: it also guides the production and reception of literary texts, influences the cultural narratives we live by, drives the development of (new) genres, and gives rise to what I call 'attention narratives'. Focusing on Arthur Conan Doyle's Sherlock Holmes stories, this essay shows how these 'attention narratives' connect with cultural anxieties of attention and distraction, driven mainly by technological advancements, while challenging readers' attentional capacities. They do so by creating moments of 'inattentional blindness', which help increase readers' awareness of the mechanisms of attention, while exposing cultural attention narratives that have shaped and continue to shape our perception. Given the central role of attention in cultures and narratives, there is a strong need for a cultural narratology of attention that bridges cognitive psychology, cultural studies, and literary studies. This essay offers the foundation for such an approach.
\end{abstract}

\section{Attention, please! Narratives in the attention economy}

We live in a culture of distraction. Whether tending to our multiple selves in social media or reacting to relentless push-notifications on our smartphones, the lure of 24/7 connectivity has a firm hold on most of us. The effortless access to multiple different worlds and communication channels, coupled with the desire to stay connected and receive instant gratification for our actions, makes us as 'social animals' easy prey for what Jonathan Crary has referred to as "24/7 capitalism [. . . ] in which multiple operations or attractions can be attended to in near-simultaneity, regardless of where one is or whatever else one might be doing" $(2013,84)$. While we are faced with a surplus of information propelled by digital communication techniques, our time and cognitive capacities are limited. Within the free market of "cognitive capitalism" (Moulier-Boutang 2011), attention has become both a key currency and scarce resource. The growing awareness of its limits has given rise 
to what has come to be known as the 'attention economy' (Davenport and Beck 2001), where the value of an object is defined by "the amount of (unpaid-for) [...] attention it has absorbed" (Beller 2006, 181).

These developments, coupled with novel opportunities afforded by digital technologies, have also affected practices of storytelling. Newly emerging genres, such as the 'internet novel', the 'email novel', or 'twitterature', tap the technological potential of digital communication. Furthermore, many of these narratives cater to what Katherine Hayles has defined as "hyper attention": a penchant for "switching focus rapidly among different tasks, preferring multiple information streams, seeking a high level of stimulation, and having a low tolerance for boredom" $(2007,187)$. According to Hayles, this lack of sustained attention is the antipode to "deep attention," "traditionally associated with the humanities [and] characterized by concentrating on a single object for long periods (say, a novel by Dickens), ignoring outside stimuli while so engaged, preferring a single information stream, and having a high tolerance for long focus” (2007, 187). As will be argued in this paper, however, anxieties of (in)attention as well as the strong link between attention and narratives are not a postmodern phenomenon. Instead, they are at the heart of both narratives and (information) cultures and can be traced across different eras.

In the following pages, I will briefly outline the concept of 'attention' and the connections between attention, culture, and narrative, before suggesting a framework for a (cultural) narratology of attention. In the latter part of the essay, I will turn to Arthur Conan Doyle's Sherlock Holmes stories as a prominent example of what I refer to as attention narratives. These narratives, in their time deeply embedded in the economy of attention, address and also counter anxieties of attention by disclosing the mechanisms of attention, conveying strategies of attentional focus, and involving readers in attentional challenges prompted by specific narrative devices. In responding to discourses on attention toward the end of the nineteenth century, Conan Doyle's stories revolve around key aspects of human (in)attention that remain relevant and, indeed, contribute to the stories' ongoing appeal.

While attention research is a growing area in psychology (see Nobre and Kastner 2014), philosophy (see Nanay 2016), and art history (see Crary 1999), literary and cultural studies have not yet deeply engaged with this field. Although some studies that explore what can be termed 'literary attention' exist, a (cultural) narratology of attention still needs to be established. For this approach, cultural studies and narratology must join forces. The objective of a cultural narratology of attention will be twofold: first, it will offer the tools for the systematic analysis of the narrative forms and structures that elicit (or inhibit) attention and their connection to the cultures of 
attention in which these narratives were created and communicated; secondly, it will assess the function of narratives in different attention economies, both within and across various eras, by examining the ways in which narratives have been shaped by, and have contributed to shaping, attention cultures.

The lack of such an approach is all the more surprising, given that principles of attention guide "social practices of real-world storytelling in different discourses and institutions” (Nünning 2012, 164). If, as claimed by Kenneth Rogers, attention can be conceptualized as "a transactional reality, which [...] shapes a transferential site where external technologies of power encounter the self” (2014, 20-21), narratives serve as an important means for reflecting upon technologies of attention, anxieties of (in)attention, and "the notion of an attention economy as a new human capital strategy" (2014, 194), while at the same time "negotiating a crisis of the self that is increasingly managed, mediated and controlled by technologies" $(2014,2)$.

In this context, the attention to attention and 'attention narratives' in particular, i.e. narratives that revolve around key aspects of attention and that challenge readers' attentional capacities, might be regarded as part of a counter-movement to the "internal (mental) and external (ecological) exhaustion" (Doran 2017, 52) effected by neoliberal capitalism, insofar as these narratives advocate the reestablishing of a "relation to the self" (Doran 2017, 56) by scrutinizing cultural anxieties of (in)attention and unveiling key strategies of attention and attention management. In fact, narratives of attention have often emerged from crises of attention. Their notable increase in recent decades can be explained on the one hand by the growing public awareness of cognitive impairments, partly driven by the "ADHD industry" (Rogers 2014, 166), and on the other by the increased attention being paid "to a contemporary form of governmentality conditioned by the resurgence of political and economic liberalism, the rise of biocapitalism, and the rapid mutations of media technology in the digital information economy" (Rogers 2014, 2). A cultural narratology of attention based on approaches from literary and cultural studies, therefore, is a profoundly cross-disciplinary endeavor drawing on existing research on attention in the disciplines of cognitive and cultural psychology, philosophy, art history, and media studies.

\section{Attention, culture, and narrative}

Although not a unitary phenomenon, and therefore hard to define, attention is generally conceived as referring to the selection of a subset of the multiple 
impressions perceived by the human senses. Bombarded with numerous and diverse stimuli that we cannot process in their entirety, our brain has to filter the sensory input to allow us to successfully navigate our environment. Attention has been conceived as "bottlenecks in perception" (Nobre and Kastner 2014, 1201), which regulate the information entering our working memory and prevent us from cognitive overload. It can, therefore, be regarded as a biological necessity.

To conceptualize the complex processes involved in attention, scholars distinguish between stimulus-driven or bottom-up, and goal-driven or top-down attention (see Pinto et al. 2013). Whereas the first type of attention is exogenous and involuntary, the latter is endogenous and more sustainable, as it is directed by voluntary control (see Carrasco 2011). While some - especially exogenous processes in attention are considered universal (Pinto et al. 2013), patterns in endogenous attention are guided by "knowledge, expectation, motivation, feelings, values and goals" (Masuda 2017, 2) and are thus shaped by our cultural environments. This is confirmed by studies comparing attention patterns in participants from America and Japan. Involving various tasks that require the description of visual scenes, these studies suggest that American participants pay greater attention to focal objects and foregrounded information, while Japanese participants tend to integrate focal and contextual information. These findings connect with earlier studies that distinguish between two different thinking styles, the analytic and the holistic (see Nisbett 2003, also Masuda 2017) associated with Western and Asian cultures respectively (Nisbett 2003, 82).

What is particularly interesting is that these studies take "people's narrative styles as an indicator of their attention" (Masuda 2017, 2), claiming that "constructing narratives tends to activate culturally dominant modes of attention" (Masuda 2017, 3). There is, of course, a structural difference between spontaneously (re)produced narratives and carefully composed (literary) narratives that have gone through several editing processes. For the analysis of attention cultures, however, the latter might be even more revealing, as they constitute key "cultural products", which "reflect [a] culture's dominant meaning system" (Masuda 2017, 6) and "can also shape psyches, as they reinforce or prime particular ways of thinking, valuing, or feeling” (Morling and Lamoureaux 2008, 213).

In addition to providing insight into dominant notions of attention within a particular culture at a specific time, narratives may help shape readers' attentional capacities by promoting mindfulness. The latter has been described as "intentionally knowing and choosing what the attention is directed to" or "attention regulation" (Hassed 2014, 631). It is important to note that mindfulness and attention require both the ability to focus and the ability to let the mind wander. After all, tension cannot exist without its counterpart of (temporary) 
release: distraction "is not the opposite of attention [but] simply marks a disruption [.. .] in its rhythms” (Phillips 2016, 128).

A cultural narratology of attention must, therefore, not only take into account the different ways in which narratives respond to and negotiate cultural, political, psychological, and philosophical discourses on attention: it must also consider the interplay of attention and distraction created in these narratives in the interests of cognitive release, and even of mind-wandering - moments which are themselves, in addition to fostering creativity and problem-solving skills, a prerequisite for attention (see Baird et al. 2012).

\section{Developing a cultural narratology of attention}

Some initial starting points for developing a cultural narratology of attention are provided by recent approaches to 'literary attention' in contexts ranging from distraction in eighteenth-century literature (Phillips 2016) and the poetics of attention in eighteenth-century (Koehler 2012) and Romantic poetry (GurtonWachter 2016), through the desire for attention to the everyday in post-1945 American poetry (Epstein 2016), to attentive reading and the mega-novel (Letzler 2017). To establish a narratology of attention that contributes to the field of critical attention studies as represented by Crary (1999), Hayles (2007), Beller (2006), and Rogers (2014), the works by Phillips and Letzler - together with initial linguistic studies on devices used to control readers' attention (Emmott et al. 2013) - are particularly relevant.

Concerned with both literary attention and distraction, these studies confirm the close bond between narrative and attention. After all, ancient rhetoric revolved around strategies to draw in and bind listeners (see Möller 2013): all texts are essentially composed to attract attention. What characterizes narratives of attention, however, is their rooting in discourses of attention at a specific time. The poetics of attention in Romantic poetry, for instance, is closely linked with the late eighteenth-century political discourse of watchfulness and "the militarization of attention" (Gurton-Wachter 2016, 5) that was driven by fear of a possible French invasion - an anxiety countered at the time by literary attention, which "allow[ed] readers to notice the neutral, overlooked, or untouched" (GurtonWachter 2016, 193). In a similar vein, "the obsessive attention to concrete, daily experience" (Epstein 2016, 219) in post-WW2 American poetry expressed a "political critique of capitalist, consumerist American culture" (Epstein 2016, 220), insofar as it aimed "to puncture the aura of triviality that masks the political realities and profound truths of everyday life” (Epstein 2016, 274). 
Considering the interconnection between aesthetic and political modes of attention and drawing on Frederic Jameson's notion of the "ideology of form" (1981, 90; see Nünning 2012, 167), I would argue that the development of literary genres is also fundamentally guided by changing discourses of attention. Although more research has to be conducted to substantiate the link between attention and genre development, the connection is confirmed, for instance, by Gothic fiction, which both prompts and exhibits forms of attentional excess, as well as the dangers of intense fixation (see Phillips 2016, 137-139) and fascination (see Baumbach 2015, Ch. 4). The focus on attention and its strategies in these narratives counters anxieties about the absorbing effects of reading, the monstrosity of modern technologies, and the crisis of perception, all of which revealed a growing awareness of the "constitutive role played by various forms of technical and cognitive mediation in the mind's perception of the external world" (Drury 2017, 145).

The rise of the short story is also closely connected with a crisis of perception and a concomitant anxiety of attention to which they responded not by encouraging attentional excess but by channeling and refining readers' attentional capacities. The proliferation of this genre in the late nineteenth century ${ }^{1}$ coincided with the emergence of a modern "capitalist consumer economy" (Crary 1999, 33) and was accompanied by "an ongoing crisis of attentiveness" (Crary 1999, 13):

[T] he changing configurations of capitalism continually push attention and distraction to new limits and thresholds, with an endless sequence of new products, sources of stimulation, and streams of information, and then respond with new methods of managing and regulating perfection. (Crary 1999, 13-14)

In our contemporary attention economy we can witness similar effects. Indeed, the crisis of attention in the nineteenth century went hand-in-hand with new theories of attention, most notably William James' The Principles of Psychology (1950 [1890]). The short story, which found the perfect home in periodicals, catered to shorter attention spans. This quality made it preferable to the novel which, as Edgar Allan Poe remarked, “cannot be read at one sitting”, thus "depriv[ing] itself [...] of the immense force derivable from totality" $(1863,197)$. I will return to the connection between the short story and attention in the final part of this essay.

The analysis of attention narratives starts with the identification of "attractors”. As defined by Peter Stockwell, "an attractor is a figural, trajector element

1 As H.G. Wells remarked in relation to the 1890s, "[s]hort stories broke out everywhere" (1914, v). 
that claims most readerly attention on the basis of, among other factors, agency, topicality, human-scale, brightness, size, noisiness, danger, and so on" (2014, 24). Stylistic features that have been identified as capturing attention include foregrounding devices such as italics, alliteration, unusual metaphors, repetition, or fragmentation (see Emmott et al. 2013). For digital fiction, mediaspecific features such as sound, images, the level of reader participation, and interface design have to be taken into account (see Bell et al. 2013), as well as distractors, including hyperlinks, which interrupt the linear flow of reading and add to readers' cognitive load (see Hayles 2010, 68).

Further "attention-controlling” (Emmott et al. 2003, 21) mechanisms range from generic expectations to scripts and schemata that relate to readers' preknowledge and culturally-determined processes of understanding. Insofar as characters describe moments of deep attention or distraction, reveal some kind of attention deficit, comment on their own or other characters' proneness to distraction or their talent for (or lack of) concentration, and create moments of joint attention (see Tobin 2008) by directing the gaze to specific objects or other characters, they can also be regarded as attention-drawing and -controlling devices within a narrative.

Characters can further serve as attractors if they point to the narrative's attentional (or distractive) qualities in metafictional twists, as Laurence Sterne's Madam Reader does in The Life and Opinions of Tristram Shandy, Gentleman (1759) or Ian McEwan's Briony in Atonement (2001). Further attractors include images of attention, both literal and metaphorical, such as the microscope (Phillips 2016, 136) or the magnifying glass, which announce or prepare a scene of intense focus.

Attention is also the guiding principle in character construction and constellation, inasmuch as it regulates what Alex Woloch (2003) calls 'character-space', i.e. the space a character occupies at the expense of other characters. Characterization, therefore, should involve the analysis of the disjunctions between "a distributed pattern of attention" in the story and "the formed pattern of attention in the discourse" (Woloch 2003, 41), i.e. between the implied potential of a character and the space that character inhabits in a narrative compared to other characters. The results will yield important insights into the dynamics of character arrangement within narrative texts, in addition to the "social rhythms" (Levine 2015, 53) that regulate the tempi of social experience.

One of the hallmarks of attention narratives, as defined here, is their ability to draw attention to attention and its limitations - the latter property by violating strategies for keeping readers' attention. Paraphrasing Viktor Shklovsky's remark on Tristram Shandy (1759) - "it is the consciousness of form through its violation that constitutes the content of the novel" (Shklovsky 1991, 149) - one 
could argue that it is the consciousness of attention through its violation that constitutes attention narratives.

Violations of form include "layered syntax, plotlines, and cognitive breaks" (Phillips 2016, 99) of the sort that characterize non-linear or disrupted narratives. Cognitive breaks can be instigated by shifts in perspective, time, or space. They predominantly occur in first-person narratives and are often triggered by narrators' digressions. As in Tristram Shandy, these detours, which Sterne refers to as "the life, the soul of reading" (1832 [1759], 64), may be marked by dashes in the text which indicate "junctions between overlaid narrative threads and thoughts, building a sense of synchronous cognition" and suggest "the interruptions, or focal rests, produced as the mind becomes overloaded" (Phillips 2016, 104). What Phillips calls "[f]ragmented rhythms of scattered attention" $(2016,98)$ can also be traced in many modern and postmodern narratives from Virginia Woolf's Mrs Dalloway (1925) to David Llewellyn's Eleven (2006), where the aesthetics of fragmentation points to an attempt to refocus attention after the traumatic experience of war and terror.

In principle, such "multifocal narrative[s]" (Phillips 2016, 105) illustrate the possibility of "parallel processing” (Phillips 2016, 110) of information, demanding (and confirming readers' capacity for) divided attention, i.e. the ability "to perform two or more tasks or process two or more sources of information concurrently" (Zanto and Gazzaley 2014, 939). As scholars have argued, reading is essentially an act of "double" (Gurton-Wachter 2016, Ch. 1) or "divided" (Phillips 2016, 206) attention, for it includes several parallel processes from "letter [and] morpheme recognition, [...] all the way up to conflict resolution within the lexicon” (Dehaene 2009, 51), as well as activities such as gap-filling (Iser 1978) and mental simulation (Green and Donahue 2012). Unless the narrative draws attention to these processes, they do not interfere with, but rather support immersion in a story.

Multifocal narratives, however, increase the cognitive load needed for processing and organizing the multiple pieces of information. The disruption of narrative flow with digressions may on the one hand point to the nonchronological nature of memory, but pushed to extremes it indicates an overload of (the narrator's) working memory and unduly stretches readers' cognitive capacities. Long, complex sentences, including “(1) multiple, incomplete syntactic units; (2) disorganized or poorly subordinated clauses; and (3) irregular rhythmic variations" (Phillips 2016, 114) which are impossible to parse at first reading can have a similar effect.

Though often less complex on the syntactic level, mega-novels, such as Eleanor Catton's The Luminaries (2013) or Karl Ove Knausgaard's six-part autobiography The Struggle (2009-2011), whose “ceaselessly compelling” 
narrative leaves you "interested [...] even when [...] bored" (Wood 2012), draw much of their success from their excessive demands on readers' attention. Connecting to Roland Barthes' remark that "it is the very rhythm of what is read and what is not read that creates the pleasure of the great narratives" $(1975,11)$, David Letzler has argued that mega-novels, characterized by a "distinctive combination of expansiveness and emptiness" $(2017,89)$, are training grounds for our attentional capacities because they strategically overstrain readers' working memory, forcing them to select: "Some passages should be processed closely and slowly, while others should be read more quickly; some are best read distantly, and others are best passed over entirely" $(2017,233)$. These shifts in attention, prompted by redundancies and repetitions, limited semantic complexity, an overload of long lists or references - e.g. encyclopedic fiction, such as Mark Z. Danielewski's House of Leaves (2000) - or narrative excess in representations of the quotidian (as so often in life-writing), are "cognitively beneficial" to the extent that they help readers "modulate attention in the mega-novel's controlled environment” (Letzler 2017, 233). According to Letzler, this ability is central for navigating "the more unrestrained cascades of information we regularly encounter in our everyday lives” (2017, 233). Stimulating both deep and skim reading, "the cruft of fiction" (Letzler 2017) might help nurture what Maryanne Wolf has recently described as a "bi-literate' reading brain capable of the deepest forms of thought in either digital or traditional mediums” (2018, n. p.).

Free of any 'cruft', the short story represents the opposite trend in literary attention: it seems to have done the filtering for us, offering only the most relevant information and, "read at one sitting" (Poe 1863, 197), however intense, refrains from overstraining our working memory. Nevertheless, although short stories have become increasingly popular again, propelled by the award of the Nobel Prize in Literature to Alice Munro in 2013, the most read fiction in the UK in 2018 was crime fiction (Hannah 2018, n. p.), a genre whose success is grounded not so much in a yearning for justice as in the attention games it initiates.

As Catherine Emmott, Anthony J. Sanford, and Marc Alexander have argued, "[m]ystery and detective writing relies on the manipulation of readers' attention" $(2013,47)$. To this end it has four main strategies: "(1) burying information”; “(2) the use of distractors [.. .] to direct readers' attention towards a false trail”; “(3) the use of foregrounding devices"; and "(4) the use of false reconstructions at the denouement” (Emmott et al. 2013, 47). Its great success during the crisis of perception in the late nineteenth century suggests that crime fiction is both the product of, and an antidote to cultural anxieties of (in)attention.

To further explore its potential in terms of cultural attention narratives, I will briefly turn to what is arguably the most successful example of crime fiction: Arthur Conan Doyle's Sherlock Holmes stories. Sparked by their adaptation by the 
$\mathrm{BBC}$ in England and CBS in America, these have lately experienced a revival. In addition to indicating "an ongoing crisis of attentiveness" (Crary 1999, 13), this revival, as Kyoko Takanashi has observed, “draws attention to Conan Doyle’s texts as a rich site for exploring the politics of information culture" (2017, 250). It also draws attention to attention itself, as well as to the connection between attention, culture, and narrative, and in doing so confirms the current need for a cultural narratology of attention.

\section{Defective attention and the detective turn}

Targeted especially in The Strand Magazine to a mass readership, the Sherlock Holmes stories (1887-1927) were deeply embedded in a modern economy of attention. In fact, the very invention of the character of Sherlock Holmes was attention-driven. As Doyle recalled, "it had struck me that a single character running through a series, if it only engaged the attention of the reader, would bind that reader to that particular magazine" (Doyle 2012, 95). To keep readers interested in the narratives, even if they missed one installment, Doyle designed them as a series, as deeply interconnected, yet essentially independent. In addition to operating within the machinery of nineteenth-century seriality (see Wiltse 1998, 116), the Sherlock Holmes stories foreground the art of attention through their protagonist, who introduces himself at the outset of the series as "consulting detective" (Doyle 2006, 41), directs attention to what is frequently overlooked, and shows a precision in reasoning that verges on the superhuman.

As Dr. Watson, the scientific, yet crucially inattentive observer through whom the narratives are focalized, suggests, Holmes' "cold, precise but admirably balanced mind" makes him "the most perfect reasoning and observing machine that the world has seen" (Doyle, 2005, 5). Blending man, mind, and machine, the image underlines the attention mechanisms at work in these narratives and at the same time reflects late nineteenth-century anxieties which, as Crary suggests, went hand-in-hand with "the emergence of a social, urban, psychic, and industrial field increasingly saturated with sensory input” (Crary 1999, 13):

Inattention, especially within the context of new forms of large-scale industrialized production, began to be treated as a danger and a serious problem, even though it was often the very modernized arrangements of labor that produced inattention. (Crary 1999, 13)

In addition to being a prime product of attention - a fact confirmed by the public outcry following Holmes' suggested death at the Reichenbach Falls in "The Adventure of the Final Problem" (1893) and the ensuing pressure exerted on 
Doyle by readers and magazine alike to revive the popular character (which he did eight years later in The Hound of the Baskervilles) - Sherlock Holmes served (and serves) not only as a generator of attention but also as a source of insight into its mechanisms. Responding to late nineteenth-century anxieties, the attention machinery that drives Doyle's narratives can further be read as a literary training ground for challenging and refining readers' attentional capacities. The close link between these narratives and cognitive psychology is confirmed by recent studies on memory, deduction, and attention, which refer to Doyle's stories to illustrate information processing mechanisms (see Didierjean and Gobet 2008, and especially Konnikova 2013).

Although the word 'attention' hardly occurs in the stories, Holmes' image of the 'brain attic', proposed in A Study in Scarlet (1887), points to a strong focus on techniques of attention management. In this novel, which is the first story of the series and introduces Holmes' principles of 'the art of deduction', Holmes compares the human brain to "a little empty attic, [which] you have to stock [.. .] with such furniture as you choose" (Doyle 2006, 32). The aim behind this mnemotechnic strategy is to avoid cluttering one's cognitive system, more precisely, one's long-term memory, with superfluous input:

A fool takes in all the lumber of every sort that he comes across, so that the knowledge which might be useful to him gets crowded out, or at best is jumbled up with a lot of other things, so that he has a difficulty in laying his hands upon it. (Doyle 2006, 32)

This statement connects to a claim that William James would make three years later in The Principles of Psychology when he stated, "My experience is what I agree to attend to. Only those items which I notice shape my mind without selective interest, experience is an utter chaos" (James 1950 [1890], 402).

Countering John Locke's conceptualization of the human mind as a blank slate upon which all sensual impressions are inscribed, both James and Doyle's Holmes advocate the necessity of filtering sensual input through controlled, voluntary attention; it is the latter that distinguishes 'observing' from 'seeing' (see Holmes' rebuke of Watson: "You see, but you do not observe", Doyle 2005, 10). Holmes' selection criteria do not follow any 'standards': The Copernican principle,

2 The reference to 'the art of deduction' could also be read as a first test in readerly attention, for it turns out that Holmes' mode of reasoning is not based on deduction, but rather on abduction (see Rapezzi et al. 2005). 
for instance, has no place in his 'brain attic', as it does not aid him in solving his cases. ${ }^{3}$ Instead, he follows the principle of choice, which resonates with James' statement that "[e]ach of us literally chooses, by way of attending to things, what sort of a universe he shall appear to himself to inhabit” (1950 [1890], 424).

The rejection of 'common knowledge' enables him to pay attention to what is overlooked, most notably by Dr. Watson or Scotland Yard, who rely on narratives that provide "reassurance and familiarity rather than discomfort and strangeness" (Takanashi 2017, 258). By pointing to information that might be strange yet deeply relevant, Holmes takes on the role of an indexer, ${ }^{4}$ representing a kind of "liberal professionalism [which] depends on striving for a 'cultivated detachment' in information management - one that [...] navigates the push-pull relation between data and narrative” (Takanashi 2017, 262). In this respect, the character of Sherlock Holmes might be read as introducing a new form of critical, individualized attention economy, where the ability to control and maintain one's attention, unaffected by the foci already set within "[t]he society of spectacle" (Debord 1967), reinforces the autonomous subject. The desire for autonomy in attention and attention management embodied by Holmes might well contribute to the enduring popularity of this figure.

In recent revivals of Doyle's stories, Holmes' capacities for “professional information management" (Takanashi 2017, 263) are accentuated insofar as his thought processes and cognitive databases are visualized as digital interfaces which he navigates through swiping movements that suggest controlled access to digital media. In the BBC series, produced by Steven Moffat and Mark Gatiss, Holmes' 'brain attic' becomes a 'mind palace', a metaphor which also draws on the mind-machine image inasmuch as it conceives the brain as a computer, a "hard drive” (BBC Sherlock, S1, E3: “The Great Game” (2010), 4:44-4:46) on which memories and knowledge can be stored, structured, and retrieved. Part of Holmes' 'mind palace' has been outsourced to his smartphone, which serves as an extended mind through which he can tap the full potential of the internet. Unlike the world wide web, but quite like the attic, the 'mind palace' has only limited storage space ("I have to delete something”, BBC Sherlock, S3, E2: "The

3 Holmes' disregard of the Copernican system could also be read as a depreciation of a treatise by his adversary James Moriarty, who may have been modeled on the Canadian-American astronomer Simon Newcomb, who had published on The Motion of the Moon (1878) and Popular Astronomy (1878) (see Shreffler 1989).

4 Indices became increasingly popular towards the end of the nineteenth century, following the foundation of the Index Society which aimed "[t]o direct public attention to a neglected subject” (Wheatley 1878, 38; see Takanashi 2017). 
Sign of Three" (2014], 01:13:06-01:13:10). The key difference between the 'brain attic' and the 'mind palace', however, is that the latter is made accessible to viewers, whereas the former is a closed mental space, albeit one whose design is suggested through descriptions (by both Watson and Holmes) and to some extent replicated in Doyle's narratives through an acute attention to detail.

What further complicates access to Holmes' brain attic is the fact that Doyle's stories are told from the viewpoint of Dr. Watson. Though the narratives include long sequences of direct speech by Holmes, which provide an impression of immediacy, these are recalled by the doctor. Watson, however, is a reliable narrator and attends closely to Holmes, which underscores the strong attraction exerted by the detective: "His very person and appearance were such as to strike the attention of the most casual observer. [...] His eyes were sharp and piercing [...] and his thin, hawk-like nose gave his whole expression an air of alertness and decision" (Doyle 2006, 29). While Watson presents Holmes as the embodiment of attention, he fears that he himself, however, might be regarded "as a hopeless busybody" (Doyle 2006, 30). As if to excuse himself for his infatuation with this figure, Watson urges us, his readers, to consider the attentional void that had dominated his life prior to the encounter with the detective: "how objectless was my life, and how little there was to engage my attention" (Doyle 2006, 30). Where Holmes serves as attractor, Watson adopts a dual position as both distractor and attractor. As narrator, he channels the reader's attention by zooming in and out of the center of attention and commenting on the detective's art of deduction; but he also creates instances of joint attention by recalling moments in which both Holmes and he attended closely to specific aspects of a scene.

The BBC series counters this mode of 'deep', singular and, to some extent, filtered attention by diminishing Watson's role as attention-controlling narrator of a blog he writes, thus providing viewers direct access to all the characters that appear and allowing them access to Holmes' 'mind palace'. Numerous cross-cut shots, overlaying graphics, floating texts, and slow-motion effects are used to visualize Holmes' thought processes and to blend searches in various mental databases and maps as a means to creating what appears to be an ideal human-technology interface. The image of the digitalized brain, tailored to an audience used to switching its attention between multiple media, further blurs the line between man and machine and presents instances of controlled attention. Coupled with stage shifts in (camera) perspective, reverse shots, and quick scene transitions, these techniques demand viewers' divided attention. As a result, they stimulate parallel processing to a greater extent (due to their more rapid succession) than multifocal narratives, and engage viewers in an 'attention machine' that caters to 
what Katherine Hayles (quoted above) has identified as a dominating trend toward "hyper attention" (2007, 187).

The hyper-attention scenes included in the BBC adaptation emphasize that the Sherlock Holmes stories continue to respond to a desire for attentional control - belying the fact, of course, that the BBC series (not unlike Doyle's stories) is part of a greater media machinery governed by the attention economy. That this point could be missed might be regarded as a form of 'inattentional blindness', which the Sherlock Holmes stories ironically try to expose and work against. The term, coined by Arien Mack and Irvin Rock (2000) in connection with experiments in visual perception, refers to the (natural) tendency to miss important information while focusing intensely on one specific task or aspect; after all, it is impossible to attend to all stimuli present. Christopher Chabris and Daniel Simons have illustrated this psychological phenomenon with the by now well-known 'gorilla experiment' $(2010$, 5-6) in which a video is played showing six people, three dressed in white, three in black. The two groups pass a basketball between them and viewers are asked to count the number of times the players in white pass the ball. While focusing on this task, half of the viewers fail to notice a person dressed in a full-body black gorilla costume who slowly walks across the scene and even stops in the middle of the action to thump its chest.

As argued by Chabris and Simons, 'inattentional blindness' is "not just limited to visual attention" (2010, 39), but exposes a widespread "illusion of attention" (2010, 41), which consists in the belief that we see everything, even though our attention is selective and highly restricted. This illusion of attention - which Chabris and Simons describe as "a necessary, if unfortunate, by-product of the normal operation of attention and perception" (2010, 38) - is exploited in detective and crime fiction. In fact, quite a few of Doyle's narratives include information that, if attended to, might have revealed the solution to a case quite early on in the story.

A prime example is "The Adventures of Silver Blaze", a short story published in The Strand Magazine in 1893, where Holmes investigates the case of a missing racehorse, Silver Blaze, and the murder of its trainer, John Straker. The short story includes multiple red herrings that might point to the murderer, including a group of Gypsies who disappeared after the events. As it turns out, however, the key to solving the case was obvious but overlooked. This is pointed out by Holmes in what is presented as an attentional challenge to the police officer, Inspector Gregory, who earlier in the story had already missed some evidence at the crime scene (see Doyle 2005, 404). The challenge begins with a clue provided by Holmes, consisting of the information that three sheep in the neighborhood of the crime scene had recently gone lame. It 
is followed by a hint concerning the non-reaction of the watchdog at the stables:

\footnotetext{
"Gregory, let me recommend to your attention this singular epidemic among the sheep." [. . . ] I saw by the Inspector's face that his attention had been keenly aroused. [. . .] "Is there any other point to which you would wish to draw my attention?"

"To the curious incident of the dog in the night-time."

"The dog did nothing in the night-time."

"That was the curious incident”, remarked Sherlock Holmes. (Doyle 2005, 411)
}

This short dialogue leaves the inspector, Watson, and also the reader baffled. Instead of offering an explanation, the next paragraph introduces a shift in time and place: "Four days later Holmes and I were again in the train" (Doyle 2005, 412). By zooming out of what is (almost) offered as the solution to the case, Watson leaves the reader time and space to solve the riddle before presenting its resolution toward the end of the story, when Holmes points out that the dog did not bark because it must have known the person who abducted the horse. This leads him to conclude that it must have been the trainer himself who kidnapped Silver Blaze. He adds that Straker must have turned against his employer and tried to prevent the horse from winning. Sensing the danger of being hurt, Silver Blaze lashed out, killing Straker, when he tried to nick its tendon - a method that he had previously tested on sheep, hence the lame sheep in the stable's vicinity (see Doyle 2005, 416-417).

The dialogue between Holmes and the Inspector centers on 'attention'. The repeated use of the noun emphasizes the need to focus (without overstretching the tension due to the playful tone of this exchange), while creating an instance of joint attention to three lame sheep and a dog's non-reaction - seemingly trivial aspects considering the kidnapping and murder that need to be solved. The foregrounding of 'attention' in this dialogue highlights its previous lack. At the same time, it reveals an instance of inattentional blindness on the part of the characters, but also of the reader, who could potentially have deciphered the "curious incident of the dog in the night-time" even before it was revealed by Holmes.

The planting of hidden clues that make the solution plausible is a common feature in well-crafted crime fiction. To a greater extent than readers of individual detective narratives, however, readers of a series such as the Sherlock Holmes stories, which are deeply infused with mechanisms of attention and attention management, become gradually attuned to attention-controlling mechanisms. Attention narratives such as "Silver Blaze", therefore, help increase readers' awareness of the clues dispersed across the narrative, refining their attentional capabilities, and also alerting them to the human proneness to inattention. 


\section{Conclusion and outlook}

The potential of detective fiction to foreground issues of attention is further confirmed by twenty-first-century novels that draw on the success of the genre in this respect. Two popular examples are Mark Haddon's The Curious Incident of the Dog in the Night-Time (2003) and Emma Healey's Elizabeth Is Missing (2014). Both first-person narratives are written in the tradition of detective fiction and foreground minds that are commonly regarded as defective. Healey's narrator, Maud, suffers from dementia and is confined to her increasingly flawed perception of the world, which ironically belies her detective qualities, for it is these that lead to the solving of a long-forgotten murder. While Elizabeth Is Missing can be read as a plea for a change of perspective in our perception of attentional 'deficits', Haddon's narrative goes a step further. Although showing symptoms that might be associated with Asperger's syndrome, Christopher, the 15-year-old narrator in The Curious Incident, is acutely attentive to details which commonly go unnoticed. This also enables him to eventually solve the mystery surrounding the death of his neighbor's dog. Ironically, what aids him in his endeavor is narrative, more precisely "a murder mystery novel” (Haddon 2003, 5), which he composes following all the tricks of the trade, including a beginning "with something to grab people's attention" (Haddon 2003, 5). The multimodal narrative is suffused with numerous distractions provided by the narrator, which are, however, identified as such, as Christopher comments on his proneness to mind-wandering throughout the story.

As I have argued elsewhere (Baumbach 2019, forthcoming), Haddon's novel emphasizes the crucial role of storytelling in creating instances of attention and mind-wandering which expose mechanisms of attention, prompt shifts in perspective, and help readers reconsider and refine their attentional habits. Furthermore, the novel draws attention to our own attentional illusion. This is already indicated by the title, which is a direct reference to the attention scene in Doyle's "Silver Blaze" story described above, and as such announces an incident of inattention even before the narrative sets in. However, not only readers unfamiliar with that story tend to overlook the hint. Focusing on the 'mystery' and on signs of Christopher's cognitive 'impairment' to which the novel seems to draw attention, we may miss more than just the clue that the dog was killed by a person familiar to it: conditioned by the grand narratives of attention disorder from the "ADHD industry" (Rogers 2014, 166), we also tend not to notice that the narrative confronts us with our own misconception of attention 'deficits', exposing a perhaps more significant inattentiveness. This, Chabris and Simons argue, is also a product of our digital environment, prompted by "devices that require 
greater amounts of attention, more and more often, with shorter and shorter lead times" (2010, 37). They conclude that, although it is impossible to eliminate "the illusion of attention", it is crucial to become aware of it and "to take steps to avoid missing what we need to see” (Chabris and Simons 2010, 41).

By drawing attention to attention, narratives both record and create such an awareness. Deeply embedded in (changing) attention economies, they help unveil mechanisms of attention and attention management, while prompting but also countering tendencies to inattentional blindness. A cultural narratology of attention will provide the tools for examining the multiple levels upon which narratives have been deeply engaged in negotiating dominant discourses of attention and challenging readers' attentional capacities and illusions. It will enable us to scrutinize the attention narratives we live by, addressing, dissecting, and eventually overcoming our inattentional (but also attentional) blindness to the cultural, social, political, and individual attention deficits those narratives both conceal and expose. Ultimately, a cultural narratology of attention will confront us with our own attention complexes and makes us attend to them by urging us to "look for the invisible gorillas in the world around [us]" (Chabris and Simons 2010, 241).

\section{References}

Baird, Benjamin, Jonathan Smallwood, Michael D. Mrazek, Julia W.Y. Kam, Michael S. Franklin, and Jonathan W. Schooler. "Inspired by Distraction: Mind Wandering Facilitates Creative Incubation.” Psychological Science 23.10 (2012): 1117-1122.

Barthes, Roland. The Pleasure of the Text. Transl. Richard Miller. New York: Farrar, Strauss and Giroux, 1975.

Baumbach, Sibylle. "The Attention Economy and the Novel." New Approaches to the TwentyFirst-Century Anglophone Novel. Eds. Sibylle Baumbach and Birgit Neumann.

Basingstoke: Palgrave Macmillan, 2019 (forthcoming).

Baumbach, Sibylle. Literature and Fascination. Basingstoke: Palgrave Macmillan, 2015.

Bell, Alice, Astrid Ensslin, and Hans Rustad. Analyzing Digital Fiction. New York: Routledge, 2013.

Beller, Jonathan. The Cinematic Mode of Production: Attention Economy and the Society of the Spectacle. Lebanon: University Press of New England, 2006.

Catton, Eleanor. The Luminaries. London: Granta Publications, 2013.

Carrasco, Marisa. "Visual Attention: The Past 25 Years." Vision Research 51.13 (2011): 1484-1525.

Chabris, Christopher and Daniel Simons. The Invisible Gorilla. How Our Intuitions Deceive Us.

New York: Crown Publishers, 2010.

Crary, Jonathan. 24/7. Late Capitalism and the Ends of Sleep. London: Verso Books, 2013.

Crary, Jonathan. Suspensions of Perception: Attention, Spectacle and Modern Culture. Cambridge, Mass.: MIT Press, 1999.

Danielewski, Mark Z. House of Leaves. New York: Pantheon, 2000. 
Davenport, Thomas, and John Beck. The Attention Economy. Understanding the New Currency of Business. Brighton, Mass.: Harvard Business School Press, 2001.

Debord, Guy. The Society of Spectacle. Trans. Donald Nicholson-Smith. New York: Zone Books, 1967.

Dehaene, Stanislas. Reading in the Brain: The Science and Evolution of a Human Invention. New York: Viking, 2009.

Didierjean, André, and Fernand Gobet. "Can Sherlock Holmes Help Cognitive Psychology?" The Psychologist 21.10 (2008): 858-859.

Doran, Peter. A Political Economy of Attention. London: Routledge, 2017.

Doyle, Arthur Conan. The New Annotated Sherlock Holmes. Vol. 1. Ed. Leslie S. Klinger. New York: Norton, 2005.

Doyle, Arthur Conan. The New Annotated Sherlock Holmes. Vol. 3. Ed. Leslie S. Klinger. New York: Norton, 2006.

Doyle, Arthur Conan. Memories and Adventures. Cambridge: Cambridge University Press. 2012.

Drury, Joseph. Novel Machines: Technology and Narrative Form in Enlightenment Britain. Oxford: Oxford University Press, 2017.

Emmott, Catherine, Anthony J. Sanford, and Marc Alexander. "Rhetorical Control of Readers' Attention: Psychological and Stylistic Perspectives on Foreground and Background in Narrative." Stories and Minds. Cognitive Approaches to Literary Narratives. Eds. Lars Bernaerts, Dirk de Geest, Luc Herman, and Bart Vervaeck. Lincoln: University of Nebraska Press, 2013. 39-58.

Emmott, Catherine, Anthony J. Sanford, and L.I. Morrow. “Towards a Theory of Reading in the Age of Cognitive Science: Cross-Disciplinary Perspectives on Narrative from Stylistics and Psychology." Belgian Journal of English Language and Literatures, New Series 1 (2003): 17-30.

Epstein, Andrew. Attention Equals Life: The Pursuit of the Everyday in Contemporary Poetry and Culture. Oxford: Oxford University Press, 2016.

Green, Melanie C., and John K. Donahue. "Simulated Worlds: Transportation into Narratives." Handbook of Imagination and Mental Simulation. Eds. Keith D. Markman, William M.P. Klein, and Julie A. Suhr. New York: Psychology Press, 2012. 241-254.

Gurton-Wachter, Lily. Watchwords: Romanticism and the Poetics of Attention. Stanford: Stanford University Press, 2016.

Haddon, Mark. The Curious Incident of the Dog in the Night-Time. London: Vintage, 2003. Hannah, Sophie. "It's No Mystery that Crime is the Biggest-Selling Genre in Books." The Guardian, 12 April 2018.

Hassed, Craig. "Training the Mindful Health Practitioner: Why Attention Matters." The Wiley Blackwell Handbook of Mindfulness. Eds. Amanda le, Christelle T. Ngnoumen, and Ellen J. Langer. Malden: Wiley and Sons, 2014. 630-648.

Hayles, Katherine N. "Hyper and Deep Attention: The Generational Divide in Cognitive Modes". Profession 1 (2007): 187-199.

Hayles, Katherine N. “How We Read: Close, Hyper, Machine.” ADE Bulletin 150 (2010): 62-79. Healey, Emma. Elizabeth Is Missing. New York: HarperCollins, 2014.

Iser, Wolfgang. The Act of Reading: A Theory of Aesthetic Response. London: Routledge and Kegan Paul, 1978.

James, William. Principles of Psychology. New York: Dover, 1950 [1890].

Jameson, Frederic. The Political Unconscious: Narrative as Socially Symbolic Act. Ithaca: Cornell University Press, 1981. 
Koehler, Margaret. Poetry of Attention in the Eighteenth Century. Basingstoke: Palgrave Macmillan, 2012.

Konnikova, Maria. Mastermind: How to Think Like Sherlock Holmes. Edinburgh: Canongate, 2013. Letzler, David. The Cruft of Fiction: Mega-Novels and the Science of Paying Attention. Lincoln: University of Nebraska Press, 2017.

Levine, Caroline. Forms: Whole, Rhythm, Hierarchy, Network. Princeton: Princeton University Press, 2015.

Llewellyn, David. Eleven. Bridgend: Seren, 2006.

Mack, Arien, and Irvin Rock. Inattentional Blindness. Cambridge, Mass.: MIT Press, 2000.

Masuda, Takahiko. "Culture and Attention: Recent Empirical Findings and New Directions in Cultural Psychology.” Social and Personality Psychology Compass 11.12 (2017): e12363.

McEwan, Ian. Atonement. London: Vintage, 2001.

Möller, Melanie. Ciceros Rhetorik als Theorie der Aufmerksamkeit. Heidelberg: Winter, 2013.

Morling, Beth, and Lamoureaux, Marika. "Measuring Culture Outside the Head: A MetaAnalysis of Individualism-Collectivism in Cultural Products." Personality and Social Psychology Review 12 (2008): 199-221.

Moulier-Boutang, Yann. Cognitive Capitalism. Transl. Ed Emery. Cambridge: Polity Press, 2011. Nanay, Bence. Aesthetics as Philosophy of Perception. Oxford: Oxford University Press, 2016. Nisbett, Richard E. The Geography of Thought. New York: Free Press, 2003.

Nobre, Anna C., and Sabine Kastner. "Attention: Time Capsule 2013." The Oxford Handbook of Attention. Eds. Anna C. Nobre and Sabine Kastner. Oxford: Oxford University Press, 2014. 1201-1222.

Nünning, Ansgar. "Narrativist Approaches and Narratological Concepts." Travelling Concepts for the Study of Culture. Eds. Birgit Neumann and Ansgar Nünning. Berlin: de Gruyter, 2012. 145-183.

Phillips, Natalie M. Distraction: Problems of Attention in Eighteenth-Century Literature. Baltimore: Johns Hopkins University Press, 2016.

Pinto, Yair, Andries R. van der Leij, Ilja G. Sligte, Victor A.F. Lamme, H. Steven Scholte. "Bottomup and Top-Down Attention Are Independent." Journal of Vision 13.16 (2013): 1-14.

Poe, Edgar Allan. The Works. 4 Vols., Vol. 3. New York: W. J. Widdleton, 1863.

Rapezzi, Claudio, Roberto Ferrari, and Angelo Branzi. "White Coats and Fingerprints: Reasoning in Medicine and Investigative Methods of Fictional Detectives." British Medical Journal 331.7531 (2005): 1491-1494.

Rogers, Kenneth. The Attention Complex. Media, Archaeology, Method. Basingstoke: Palgrave Macmillan, 2014.

Sherlock. "The Great Game” (S1, E3). Produced by Steven Mofatt and Mark Gatiss. BBC, 2010.

Sherlock. "The Sign of Three" (S3, E2). Produced by Steven Mofatt and Mark Gatiss. BBC, 2014.

Shklovsky, Viktor. Theory of Prose. Champaign: Dalkey Archive Press, 1991.

Shreffler, Philip A. “Moriarty: A Life Study." Sherlock Holmes by the Gas-Lamp: Highlights from the First Four Decades of The Baker Street. Ed. Philip A. Shreffler. New York: Fordham University Press, 1989. 263-270.

Sterne, Laurence. The Life and Opinions of Tristram Shandy, Gentleman. 2 Vols., Vol. 1. London: James Cochrane and Co., 1832 [1759].

Stockwell, Peter. "War, Worlds and Cognitive Grammar." Cognitive Grammar in Literature. Eds. Chloe Harrison, Louise Nuttall, Peter Stockwell, and Wenjuan Yuan. Amsterdam: John Benjamins Publishing, 2014. 19-34. 
Takanashi, Kyoko. "Sherlock's 'Brain-Attic': Information Culture and the Liberal Professional Dilemma." PMLA 132.2 (2017): 250-265.

Tobin, Vera. Literary Joint Attention: Social Cognition and the Puzzles of Modernism. Univ. Diss.: University of Maryland, 2008.

Wells, H.G. The Country of the Blind and Other Stories. London: Thomas, 1914.

Wheatley, Henry B. What Is an Index? A Few Notes on Indexes and Indexers. London: Longmans, Green \& co., 1878.

Wiltse, Ed. “'So Constant an Expectation: Holmes and Seriality." Narrative 6.2 (1998): 105-122. Wolf, Maryanne. "Skim Reading is the New Normal." The Guardian, 25 August 2018.

Woloch, Alex. The One vs. the Many: Minor Characters and the Space of the Protagonist in the Novel. Princeton: Princeton University Press, 2003.

Wood, James. "Total Recall: Karl Ove Knausgaards's My Struggle.” The New Yorker, 13 August 2012.

Woolf, Virginia. Mrs Dalloway. Oxford: Oxford University Press, 2008 [1925].

Zanto, Theodore P., and Adam Gazzaley. "Attention and Ageing." The Oxford Handbook of Attention. Eds. Anna C. Nobre and Sabine Kastner. Oxford: Oxford University Press, 2014. 927-971. 